\title{
Green Fingers: Plant Thigmo Responses as an Unexplored Area for Haptics Research
}

\author{
$\operatorname{Gijs~Huisman}^{(\bowtie)}$ \\ Amsterdam University of Applied Sciences, Digital Society School, Wibautstraat 2-4, \\ 1091GM Amsterdam, The Netherlands \\ g.huisman@hva.nl
}

\begin{abstract}
Haptics research has been firmly rooted in human perceptual sciences. However, plants, too, possess capabilities for detecting mechanical stimuli. Here, I provide a brief overview of plant thigmo (touch) perception research with the aim of informing haptics researchers and challenging them to consider applying their knowledge to the domain of plants. The aim of this paper is to provide haptics researchers with conceptual tools, including relevant terminology, plant response mechanisms, and potential technology applications to kickstart research into plant haptics.
\end{abstract}

Keywords: Plants - Thigmo - Thigmomorphogenesis ·

Mechanosensing $\cdot$ Haptics $\cdot$ Indoor farming $\cdot$ Vertical farming

\section{Introduction}

The haptics research community has been primarily focused on studying haptic technology with human subjects [26], and not without reason. Haptics research has resulted in invaluable insights into human haptic perception capabilities and innumerable technological innovations $[18,26]$.

Nevertheless, we share our daily lives with more than just humans. Haptic interactions are abundant in human-animal interaction, for example. In yet a different domain we might use our sense of touch to engage with plants, whether it be manipulating a pair of scissors to carefully sculpt a bonsai tree, or using one's hands to take down vines. Still, these are both examples from a human haptic perception perspective. Research in the biological sciences has shown that plants, too, are capable of perceiving 'touch' [36]. Think, for example, of how a bonsai tree changes its growing pattern when parts of its trunk are bound to create a more desirable shape [13]. Or think of how vines can cling to vertical surfaces, and how the Venus Flytrap (Dionaea muscipula) can detect when prey has landed on its leaf [7].

In fact, in their natural environment, plants are continuously subjected to mechanical stimuli, from soil vibrations to rain, snow, and hail, to wind, and 
contact with other nearby plants and animals [5]. With their natural environment in mind it is therefore not surprising that plants evolved to be able to detect mechanical stimulation. However, since at least the agricultural revolution, humans have been moving plants away from their natural habitat, in some specific cases even moving them indoors. We are moving plants indoors for decoration, health purposes (e.g., air quality, or mental health), and production of both decorative plants and for food production (e.g., indoor farming). In these indoor circumstances plants are no longer subjected to typical mechanical stimulation which has been shown to have clear effects on, for example, their growth rate $[6,35,36]$.

In this context haptic technology could offer opportunities to provide stimulation to plants growing indoors in order to stimulate certain types of growing behaviors. In this sense, haptic technology becomes another tool, like LED lighting, or hydroponics systems, in allowing for controlled growth of plants [4]. In the remainder of this paper I will provide an overview of key terminologies and concepts related to plant touch perception. I will discuss examples of existing plant-technology interaction and highlight cases for haptics in particular. Finally, I will discuss application domains in more detail and will provide recommendations for the haptics community in order to kickstart research into 'plant haptics'.

\section{Key Concepts in Plant Mechanosensing}

Plants have evolved to be able to respond to mechanical stimuli that occur as a consequence of their growing environment [5]. Since at least the ancient Greeks, humans have known that mechanical stimuli affect plant growth [6]. Examples of how humans have used mechanical stimuli to modulate plant growth throughout history include the originally Chinese art of bonsai [13], where the binding of branches and trunks produces desirable shapes, Mugifumi, the Japanese practice of trampling wheat and barley seeds to improve plant growth [20], and studies by Darwin [11] on the movement of plants.

Since these long-known practices and early scientific studies much progress has been made regarding understanding the cellular mechanisms that underlie plant responses to mechanical stimuli, though much remains to be discovered [6]. The locus of plant touch perception is the cytoskeleton-plasma membranecell wall interface which subsequently integrates into molecular signaling specific to the mechanical stimulus, and signal transduction [24,35]. A description of the exact cellular and molecular mechanisms that enable mechanoreception in plants is beyond the scope of this paper. The interested reader is referred to review papers on this topic $[10,24,28,35,36]$.

\subsection{Terminology of Plant Responses to Mechanical Stimulation}

In human perceptual sciences [26] as well as in engineering and computer science [18] the term 'haptic', which derives from the Greek word haptikos meaning 
'able to come into contact with', is widely used. However, in plant biology a different Greek word is used to denote physical stimulation, namely thigma [7], meaning 'touch'. This term is used in different ways to denote specific classes of plant responses to mechanical stimuli. The term thigmomorphogenesis, coined by Jaffe [23], refers to the impact of mechanical stimuli on plant growth and development [22]. These are generally slow processes and the types of thigmomorphogenic sources and effects are varied and depend on the specific plant type. The greatest potential impact of haptic technology is in eliciting thigmomorphogenic effects because these constitute permanent changes to a plant's growth and development.

A different class of responses are thigmotropic responses. These responses refer to changes in plant growth that are related to the direction of the mechanical stimulation [7]. For example, roots may grow around physical barriers or grow towards the source of a vibration [14]. Thigmotropic effects are different from thigmomorphogenic effects in that the latter refer to structural changes in the plant's growth (e.g., thicker stems, stockier plants), while the former refers to adaptation of regular growth behavior. Thigmotropic responses can happen relatively quickly and provide another interesting application domain for haptic technology.

Finally, there are thigmonastic responses. These refer to a plant's responses to mechanical stimulation that is not related to the direction of the stimulation [7]. An example is the Venus Flytrap's leaves closing in response to stimulation of its mechanosensing trigger hairs located within the leave structure [7]. Thigmonastic effects occur rapidly, but are also momentary and do not result in structural changes. Some applications for haptic technology can be conceived of but they are more limited than for the other described responses.

\subsection{Plant Responses to Mechanical Stimulation}

Physical stimuli that plants are subjected to are varied and can be both internal and external [36]. The focus here is on external forces, because those can be more easily generated using haptic technology. Nevertheless, internal forces, including sensing changes in turgor in a plant's cell and self-loading on the vertical axis of the stem or due to fruit bearing under the influence of gravity [36] (gravitropism is the term reserved for gravity's influence on a plant's growth $[10,28,36])$, all affect plant growth and may interact with external forces.

Plants can be subjected to various forms of mechanical stimulation from precipitation, animals making contact with the plant, and contact with other plants. Under natural conditions wind may be the most common and persistent external force that affects plant growth $[16,35]$. Plants', in particular trees', acclimatization to wind conditions affects their branching (e.g., trees that are predominantly subjected to wind from a single direction, such as in coastal regions, show asymmetrical branching formations), stem, and even roots [16]. Stimulation of different plant organs such as leaf brushing, bending of the stem, mechanical stresses on the roots, and contact with reproductive organs all have effects on the plants' overall development and the development of each specific organ [5-8]. In general, 


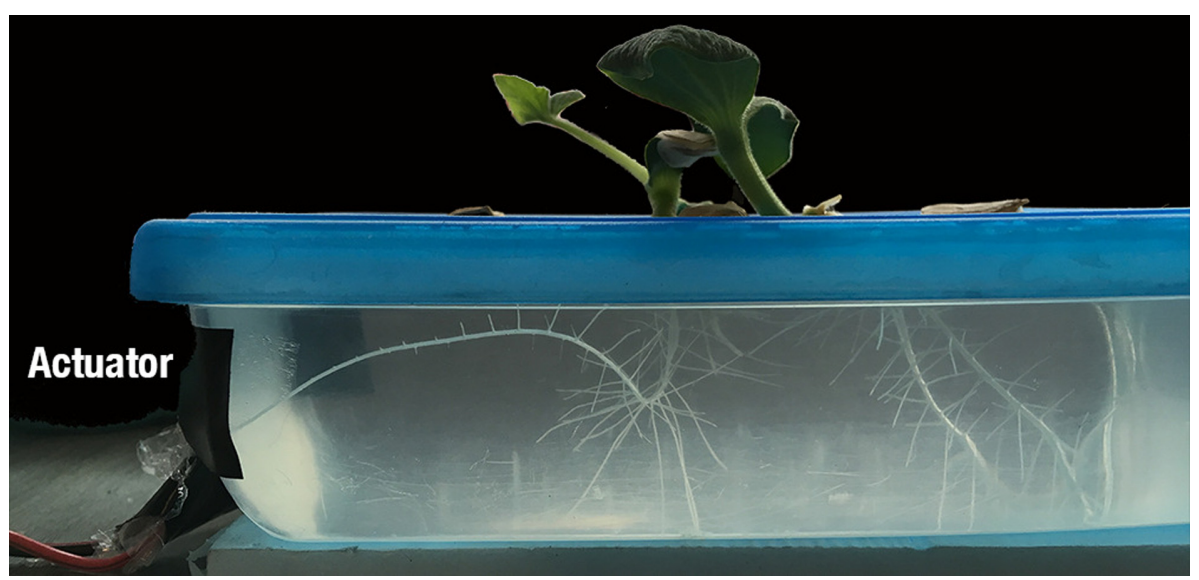

Fig. 1. A prototype with an Arduino Uno driving a Tectonic Elements TEAX25C05-8 transducer with a $250 \mathrm{~Hz}$ sine wave. The image shows results of approximately two weeks of continuous stimulation on the root orientation of pumpkin seeds (Cucurbita maxima). One root can be observed to orient towards the source of vibration. Root growth would be expected to be more diffuse without stimulation, though, note, this is a single-trial result for illustration purposes.

leaf brushing results in more compact plants, with thicker leaves, while bending of the stem in most cases results in shorter plants with shorter distances between branch nodes, an increase in width (i.e., radial growth) of the stem, and more flexible tissue [35]. These types of stimulation typically result in delay of flowering [35]. Forces exerted on a plants' leafs and stem may propagate to the roots, and, in trees at least, can result in a larger root mass [35]. In all, these adaptations to mechanical stimulation make sense in that they make plants more resilient to such stimulation in the future, while delayed flowering saves valuable resources. All of these thigmomorphogenic responses have a profound impact on plant development. Nevertheless, thigmonastic responses, especially stimulation of a plant's reproductive organs serves an important purpose as well. Flowering plants release pollen when physical stimulation by a pollinator is detected, a process referred to as buzz pollination [12].

Plants' response to mechanical stimulation may also trigger molecular and biochemical changes that serve as a defence against pests and fungi [29]. For example, stroking of a strawberry plant (Fragaria ananassa) [37] or thale cress (Arabidopsis thaliana) [3] resulted in increased resistance to a fungal pathogen. Pressure due to soundwaves (related to plant mechanosensing [36]) has been found to increase vitamin $\mathrm{C}$ and sugar, among other parameters, in tomato fruits (Solanum lycopersicum) [2], which is relevant to food production. 


\section{Plants, Touch, and Technology}

Mechanical stimulation of plants results in overall more compact, stronger, and more resilient plants, with greener leaves (for a review of effects see [6]), and may affect plant food production [2] though this latter effect is less consistent [35]. Nevertheless, plants' general characteristic responses to touch result in ornamental and food producing plants with an appearance that is preferred by consumers and retailers, and that have benefits for growers in terms of production area, packaging, and transport [6]. In addition, using mechanical stimulation to activate a plants' defence mechanism has the potential to reduce the need for chemical pesticides $[6,35]$.

Taken together, it is not surprising that researchers have created devices to automatically stimulate plants through brushing $[27,32,38]$, or vibration (see [6] for several examples). However, these efforts have not been taken up widely due to technical limitations of the systems in question $[6,35]$. Interestingly, in the bioacoustics community researchers have been using contact speakers to generate vibrations detectable by plants $[14,15]$. Lab studies have shown that roots can orient towards the source of a vibration [15], and can even navigate towards this source [14]. Figure 1 shows that such setups can be relatively easily created with basic hardware.

In computer science, primarily human-computer interaction (HCI) research, plants are used for interaction but often only as input device [30] or as a display method where mechanical stimulation is used to move the plant [17]. Only in a few cases is attention paid to a plant's responses to these types of stimulation $[25,33]$, but not as a central part of the designed system. Thus, there are opportunities for HCI designs to make plants' responses a more integral part of interactive systems (e.g., use changing growth patterns as a system's output).

\section{Green Fingers, Untapped Potential}

In nature plants respond to mechanical stimuli to adapt to their environment [35] and these responses result in an overall more desirable plant morphology [6]. Nevertheless, technical difficulties have held back developments for automation in horticulture [6,35], and there is only a nascent interest thus far in computer science to develop devices for haptic stimulation of plants $[25,33]$. Thus, there are several opportunities to investigate the role of haptic technology developed for humans [18] in providing mechanical stimulation to plants. The most straightforward application is leaf brushing with a mechanical stimulus. Sophisticated haptic devices might be able to deliver such stimuli with accurate control over the applied force and velocity of stimulation [18]. Using similar devices, or even off-the shelve components such as servo motors, stem bending might also be easily achieved. Air vortices produced by custom-built haptic devices [34] might also be used to provide brush-like stimulation and may be a less invasive method than using mechanical devices [35]. Recent advances in ultrasonic haptics [21] are of particular interest considering findings that demonstrate effects of ultrasound on plant development [1]. Ultrasonic haptic devices could be used for leaf, 
stem, root, and reproductive organ stimulation. As Fig. 1 demonstrates, applying vibrations to root structures is relatively easily achieved. Recent developments in wide-band vibrotactile actuators (e.g., Apple's Taptic Engine) might be of particular use here. In short, the haptics community is well-placed to provide novel methods and devices for applying mechanical stimuli to plants. Taking plants as an application area might result in new and unexpected opportunities for both haptics research as well as horticultural research. Here, I want to provide a few suggestions for directions in which to search for such opportunities.

First, we might consider the production of decorative and food-producing plants on a smaller scale. Indoor farming has seen quite an uptake in recent years, spurred on by developments of LED lights and hydroponic systems. With a global food system that is under severe pressure from human-made climate change, indoor farming might provide one route towards sustainable food security [4]. The use of haptic technology to provide mechanical stimulation to plants grown indoors can help produce more compact and resilient crops that require less space and less pesticides (for reviews see $[6,35]$ ). Thus, haptic technology might be another valuable tool in future food production through controlled-environment agriculture [4], especially considering that mechanical stimulation is a typical feature of plants' natural habitat [5]. Related to this, we might also consider food production in more futuristic scenarios. NASA has conducted experiments with food production in zero-G for decades and zero- $G$ environments come with specific considerations for food production [9]. From this perspective, haptic technology could be applied in such environments to help reduce some of the unwanted effects of plant growth in zero-G.

Second, haptic technology in combination with observable plant responses to such stimulation could be used for educational purposes. Plants' responses to light and nutrients might be relatively well-known, but plants' responses to touch, less so. The demonstration of thigmomorphogenic, thigmotropic, and thigmonastic effects in biology lessons could be supported by haptic systems. Especially for thigmomorphogenic effects that typically take a longer time to develop, automated haptic systems to demonstrate such effects in the classroom might be fruitful.

Third, arts and design disciplines may benefit from haptic technology for the controlled mechanical stimulation of plants. Bio-mimetic design, for instance, could use haptic technology for the creation of, not just nature-inspired designs, but designs of which nature is an active, living part. Such ideas could even be extended to architecture, where haptic technology (e.g., robotic structures that can move and apply forces) could help shape living architectural structures. For an example, see the living bridge of Cherrapunji in India. Admittedly, such ideas are still somewhat speculative although research on 'cyborg botany' might suggest they are not too far off [31].

Fourth, as already hinted at, the haptics community might be of aid to research in biology, botany, and horticulture by providing state-of-the-art technology for the application and measurement of mechanical forces that can be applied to plants. Conversely, work on plant thigmo responses could also inspire haptics researchers, for example, in the design of plant-inspired haptic systems 
(see [19] for an example of plant-mimetic mechanosensors). Here, it is also important to stress the need for collaboration in all of the examples described. While the current paper aims to prompt the interest of the haptics community in plant thigmo responses, there is a large body of literature from the biological sciences that extends and adds nuance to the topics discussed here. The haptics community has a firm grasp on the technology necessary to create breakthrough innovations in haptics research, now it is time to see if they possess green fingers too.

\section{References}

1. Aladjadjiyan, A.: Physical factors for plant growth stimulation improve food quality. In: Food Production-approaches, Challenges and Tasks, vol. 270 (2012)

2. Altuntas, O., Ozkurt, H.: The assessment of tomato fruit quality parameters under different sound waves. J. Food Sci. Technol. 56(4), 2186-2194 (2019)

3. Benikhlef, L., et al.: Perception of soft mechanical stress in arabidopsis leaves activates disease resistance. BMC Plant Biol. 13(1), 133 (2013)

4. Benke, K., Tomkins, B.: Future food-production systems: vertical farming and controlled-environment agriculture. Sustainability: Sci. Pract. Policy 13(1), 13-26 (2017)

5. Biddington, N.L.: The effects of mechanically-induced stress in plants-a review. Plant Growth Regul. 4(2), 103-123 (1986)

6. Börnke, F., Rocksch, T.: Thigmomorphogenesis-control of plant growth by mechanical stimulation. Sci. Hortic. 234, 344-353 (2018)

7. Braam, J.: In touch: plant responses to mechanical stimuli. New Phytol. 165(2), 373-389 (2005)

8. Chehab, E.W., Eich, E., Braam, J.: Thigmomorphogenesis: a complex plant response to mechano-stimulation. J. Exp. Bot. 60(1), 43-56 (2009)

9. Cooper, M., Douglas, G., Perchonok, M.: Developing the NASA food system for long-duration missions. J. Food Sci. 76(2), R40-R48 (2011)

10. Coutand, C.: Mechanosensing and thigmomorphogenesis, a physiological and biomechanical point of view. Plant Sci. 179(3), 168-182 (2010)

11. Darwin, C., Darwin, F.: The power of movement in plants. Appleton (1897)

12. De Luca, P.A., Vallejo-Marin, M.: What's the 'buzz' about? the ecology and evolutionary significance of buzz-pollination. Curr. Opin. Plant Biol. 16(4), 429-435 (2013)

13. Elias, T.: History of the introduction and establishment of bonsai in the western world. In: Proceedings of the International Scholarly Symposium on Bonsai and Viewing Stones, pp. 19-104 (2005)

14. Gagliano, M., Grimonprez, M., Depczynski, M., Renton, M.: Tuned in: plant roots use sound to locate water. Oecologia 184(1), 151-160 (2017)

15. Gagliano, M., Mancuso, S., Robert, D.: Towards understanding plant bioacoustics. Trends Plant Sci. 17(6), 323-325 (2012)

16. Gardiner, B., Berry, P., Moulia, B.: Wind impacts on plant growth, mechanics and damage. Plant Sci. 245, 94-118 (2016)

17. Hammerschmidt, J., Hermann, T., Walender, A., Krömker, N.: InfoPlant: multimodal augmentation of plants for enhanced human-computer interaction. In: 2015 6th IEEE International Conference on Cognitive Infocommunications (CogInfoCom), pp. 511-516. IEEE (2015) 
18. Hayward, V., Astley, O.R., Cruz-Hernandez, M., Grant, D., Robles-De-La-Torre, G.: Haptic interfaces and devices. Sens. Rev. 24(1), 16-29 (2004)

19. Huynh, T.P., Haick, H.: Learning from an intelligent mechanosensing system of plants. Adv. Mater. Technol. 4(1), 1800464 (2019)

20. Iida, H.: Mugifumi, a beneficial farm work of adding mechanical stress by treading to wheat and barley seedlings. Frontiers in plant science 5, 453 (2014)

21. Inoue, S., Makino, Y., Shinoda, H.: Active touch perception produced by airborne ultrasonic haptic hologram. In: 2015 IEEE World Haptics Conference (WHC), pp. 362-367. IEEE (2015)

22. Jaffe, M.: The involvement of callose and elicitors in ethylene production caused by mechanical perturbation. In: Fuchs, Y., Chalutz, E. (eds.) Ethylene, vol. 9, pp. 199-215. Springer, Dordrecht (1984)

23. Jaffe, M.J.: Thigmomorphogenesis: the response of plant growth and development to mechanical stimulation. Planta 114(2), 143-157 (1973)

24. Jaffe, M.J., Leopold, A.C., Staples, R.C.: Thigmo responses in plants and fungi. Am. J. Bot. 89(3), 375-382 (2002)

25. Kurihara, W., Nakano, A., Hada, H.: Botanical puppet: computer controlled shameplant. In: 2017 Nicograph International (NicoInt), pp. 68-71. IEEE (2017)

26. Lederman, S.J., Klatzky, R.L.: Haptic perception: a tutorial. Attention Percept. Psychophys. 71(7), 1439-1459 (2009)

27. Morel, P., Crespel, L., Galopin, G., Moulia, B.: Effect of mechanical stimulation on the growth and branching of garden rose. Sci. Hortic. 135, 59-64 (2012)

28. Moulia, B.: Plant biomechanics and mechanobiology are convergent paths to flourishing interdisciplinary research. J. Exp. Bot. 64(15), 4617-4633 (2013)

29. Pillai, S.E., Patlavath, R.: Touch induced plant defense response. J. Plant Biol. Res. 4(3), 113-118 (2015)

30. Poupyrev, I., Schoessler, P., Loh, J., Sato, M.: Botanicus interacticus: interactive plants technology. In: ACM SIGGRAPH 2012 Emerging Technologies, p. 4. ACM (2012)

31. Sareen, H., Maes, P.: Cyborg botany: Exploring in-planta cybernetic systems for interaction. In: Extended Abstracts of the 2019 CHI Conference on Human Factors in Computing Systems, p. LBW0237. ACM (2019)

32. Schnelle, M.A., McCraw, B.D., Schmoll, T.J.: A brushing apparatus for height control of bedding plants. HortTechnology 4(3), 275-276 (1994)

33. Seo, J.H., Sungkajun, A., Suh, J.: Touchology: towards interactive plant design for children with autism and older adults in senior housing. In: Proceedings of the 33rd Annual ACM Conference Extended Abstracts on Human Factors in Computing Systems, pp. 893-898. ACM (2015)

34. Sodhi, R., Poupyrev, I., Glisson, M., Israr, A.: Aireal: interactive tactile experiences in free air. ACM Trans. Graph. (TOG) 32(4), 1-10 (2013)

35. Sparke, M.A., Wünsche, J.N.: Mechanosensing of plants. Horticultural Rev. 47, 43-83 (2020)

36. Telewski, F.W.: A unified hypothesis of mechanoperception in plants. Am. J. Bot. 93(10), 1466-1476 (2006)

37. Tomas-Grau, R.H., Requena-Serra, F.J., Hael-Conrad, V., Martínez-Zamora, M.G., Guerrero-Molina, M.F., Díaz-Ricci, J.C.: Soft mechanical stimulation induces a defense response against botrytis cinerea in strawberry. Plant Cell Rep. 37(2), 239-250 (2018)

38. Zhou, J., Wang, B., Zhu, L., Li, Y., Wang, Y.: A system for studying the effect of mechanical stress on the elongation behavior of immobilized plant cells. Colloids Surf. B 49(2), 165-174 (2006) 
Open Access This chapter is licensed under the terms of the Creative Commons Attribution 4.0 International License (http://creativecommons.org/licenses/by/4.0/), which permits use, sharing, adaptation, distribution and reproduction in any medium or format, as long as you give appropriate credit to the original author(s) and the source, provide a link to the Creative Commons license and indicate if changes were made.

The images or other third party material in this chapter are included in the chapter's Creative Commons license, unless indicated otherwise in a credit line to the material. If material is not included in the chapter's Creative Commons license and your intended use is not permitted by statutory regulation or exceeds the permitted use, you will need to obtain permission directly from the copyright holder. 